\title{
Characterization of a New qQq-FTICR Mass Spectrometer for Post-Translational Modification Analysis and Top-Down Tandem Mass Spectrometry of Whole Proteins
}

\author{
Judith A. Jebanathirajah ${ }^{\ddagger \S}$ and Jason L. Pittman \\ Mass Spectrometry Resource, Department of Biochemistry, Boston University School of Medicine, Boston, \\ Massachusetts, USA
}

Bruce A. Thomson

MDS-SCIEX, Concord, Ontario, Canada

\author{
Bogdan A. Budnik* and Parminder Kaur \\ Cardiovascular Proteomics Center, Boston University School of Medicine, Boston, Massachusetts, USA
}

Michael Rape and Marc Kirschner

Department of Systems Biology, Harvard Medical School, Boston, Massachusetts, USA

\author{
Catherine E. Costello ${ }^{+}$and Peter B. $\mathrm{O}^{\prime}$ Connor $^{\dagger}$ \\ Mass Spectrometry Resource, Department of Biochemistry, Boston University School of Medicine, Boston, \\ Massachusetts, USA
}

The use of a new electrospray qQq Fourier transform ion cyclotron mass spectrometer (qQq-FTICR MS) instrument for biologic applications is described. This qQq-FTICR mass spectrometer was designed for the study of post-translationally modified proteins and for top-down analysis of biologically relevant protein samples. The utility of the instrument for the analysis of phosphorylation, a common and important post-translational modification, was investigated. Phosphorylation was chosen as an example because it is ubiquitous and challenging to analyze. In addition, the use of the instrument for top-down sequencing of proteins was explored since this instrument offers particular advantages to this approach. Top-down sequencing was performed on different proteins, including commercially available proteins and biologically derived samples such as the human E2 ubiquitin conjugating enzyme, UbCH10. A good sequence tag was obtained for the human $\mathrm{UbCH} 10$, allowing the unambiguous identification of the protein. The instrument was built with a commercially produced front end: a focusing rf-only quadrupole $(\mathrm{Q} 0)$, followed by a resolving quadrupole (Q1), and a LINAC quadrupole collision cell (Q2), in combination with an FTICR mass analyzer. It has utility in the analysis of samples found in substoichiometric concentrations, as ions can be isolated in the mass resolving Q1 and accumulated in Q2 before analysis in the ICR cell. The speed and efficacy of the Q2 cooling and fragmentation was demonstrated on an LCMS-compatible time scale, and detection limits for phosphopeptides in the $10 \mathrm{amol} / \mu \mathrm{L}$ range $(\mathrm{pM})$ were demonstrated. The instrument was designed to make several fragmentation methods available, including nozzle-skimmer fragmentation, Q2 collisionally activated dissociation (Q2 CAD), multipole storage assisted dissociation (MSAD), electron capture dissociation (ECD), infrared multiphoton induced dissociation (IRMPD), and sustained off resonance irradiation (SORI) CAD, thus allowing a variety of $\mathrm{MS}^{\mathrm{n}}$ experiments. A particularly useful aspect of the system was the use of $\mathrm{Q} 1$ to isolate ions from complex mixtures with narrow windows of isolation less than $1 \mathrm{~m} / \mathrm{z}$. These features enable top-down protein analysis experiments as well structural characterization of minor components of complex mixtures. (J Am Soc Mass Spectrom 2005, 16, 1985-1999) (c) 2005 American Society for Mass Spectrometry

Published online November 2, 2005

Address reprint requests to Dr. P. B. O'Connor, Mass Spectrometry Resource, Department of Biochemistry, Boston University School of Medicine, 715 Albany St., Boston, MA 02118-2526, USA. E-mail: poconnor@bu.edu * Mass Spectrometry Resource, Department of Biochemistry, Boston University School of Medicine, 715 Albany St., Boston MA, 02118-2526, USA.
+ Cardiovascular Proteomics Center, Boston University School of Medicine, 650 Albany St., X-116, Boston MA 02118-2526, USA.

$\ddagger$ Department of Systems Biology, Harvard Medical School, 240 Longwood Ave., Boston, MA 02115, USA.

$\S$ MDS-SCIEX, Concord, ON, Canada. 
$\mathrm{T}$ he analysis of biological polymers continuously challenges analytical techniques and the design of instruments for biological mass spectrometry. The development of soft ionization methods such as electrospray ionization (ESI) and matrix-assisted laser desorption/ionization (MALDI) [1, 2] provided the ability to analyze nonvolatile molecules such as proteins and peptides, and since then biologically derived samples continue to push the limits of the technology. Examples of these challenges include several protein modifications such as phosphorylation and glycosylation, which require extremely soft ionization conditions as well as ion source and interface parameter settings that minimize collisional activation and prevent the loss of such modifications. Thus, the provision of tunable ion sources and optics for these types of analyses is invaluable. Several other favorable attributes for an instrument designed for biological mass spectrometry include (1) increased dynamic range capabilities for the analysis of very complex mixtures, (2) improved sensitivity, (3) improved fragmentation techniques, (4) unit resolution for precursor ion selection, (5) high mass resolution, and (6) high mass accuracy.

Many mass spectrometers provide an intra-scan dynamic range of $10^{2}-10^{3}$ (3D quadrupole ion traps, quadrupole time-of-flight instruments) requiring most biologically derived samples (which may have a dynamic range of $>10^{7}$ ) to be processed through a series of lengthy and time-consuming separations to purify the sample. The dynamic range of triple quadrupole instruments and FTMS instruments is theoretically higher ( $10^{4}$ and above), allowing these types of instruments to provide more information about complex biological samples. As biological samples are often difficult and expensive to isolate, highly sensitive instruments are desired, especially when analyzing modified peptides found in substoichiometric amounts compared with their unmodified homologs.

Additional problems occur in cases where labile modifications (such as sulfation, $\mathrm{O}$-glycosylation, and phosphorylation) occur, since these are often easily lost during ionization or collisional activation. Directed fragmentation methods that leave the modification of the protein/peptide intact during fragmentation are preferred, so that the location and nature of the modification of the peptide/protein can be determined. To date, two (related) directed fragmentation processes have been described, wherein labile bonds between modifications and the amino acid side chains are not broken: electron capture dissociation (ECD) [3-5] and electron-transfer dissociation (ETD) [6]. The former process is based on the capture of thermal electrons which results in the predominant peptide cleavage at the $\mathrm{N}-\mathrm{C}_{\alpha}$ bond without fragmenting the most labile side-chain modifications [7-10]. This fragmentation method is usually performed in FTMS instruments where it has been extensively demonstrated. However, two groups have recently shown that the process can also be achieved in an ion trap [11, 12]. Electron transfer dissociation (ETD) has been introduced in linear ion traps [6]. This fragmentation method utilizes gas-phase reactions between protonated peptides and radical anions, transferring electrons upon ion-ion interaction and, thus, producing peptide fragmentation similar to ECD. For the fragmentation of large biomolecules (such as intact proteins or large peptides), the high mass accuracy and resolution associated with FTMS provides a distinct advantage over the lower resolution ion trap.

The overall benefits of high mass accuracy and resolution provided by FTICR instruments have been discussed extensively, where it is recognized that in addition to reducing false positives in peptide mass mapping and peptide sequencing experiments, better accuracy and speed are achieved for database searches [13-15]. In addition, measurements of 1 ppm mass accuracy have been shown to be adequate for determining the unique amino acid composition of peptides smaller than $600 \mathrm{Da}$, [16], with the caveat that differentiation of peptides that have the same elemental composition but contain isomeric amino acids, e.g., Leu/Ile, obviously requires high-energy $\mathrm{CAD}$ or high-energy ECD MS/MS. The use of accurate mass measurements in combination with HPLC, spawned novel methods for database searching such as the use of accurate mass tags and retention times to create databases, which can then be used for identification and quantitation purposes [17]. In addition, the recent ease of use and ability to perform high throughput bottom-up LCMS experiments using the ICR cell as a mass detector have facilitated the implementation of these measurements for routine experiments involving peptide sequencing for protein identification purposes [18]. This has given rise to another original method of determining the sequence of a peptide where accurate masses of fragment ions can be used to determine elemental composition and, hence, amino acid composition, composition based sequencing (CBS), which can be carried out, i.e., for de novo sequencing purposes [19, 20].

Accurate mass measurements are essential for topdown sequencing since the number of possible candidates for a given mass drops precipitously with increasing mass accuracy [21]. Top-down sequencing (sequencing of whole proteins) is a complementary approach to bottom-up (sequencing of peptides usually produced by proteolytic digestion of the protein of interest) [22, 23], and is becoming more widespread with the increased use of FTICR instruments that provide the resolution and accuracy required for unambiguous assignments of large, multiply charged fragment ions [24]. Although bottom-up protein analysis approaches have proven to be extremely successful and a diverse set of software tools are available for these analyses, they are normally unable to provide $100 \%$ sequence coverage, and sequence alterations and posttranslational modifications (PTMs) are often missed. Top-down approaches on the other hand provide, by definition, $100 \%$ sequence coverage since the intact protein is the starting point for the analysis. Thus, one 


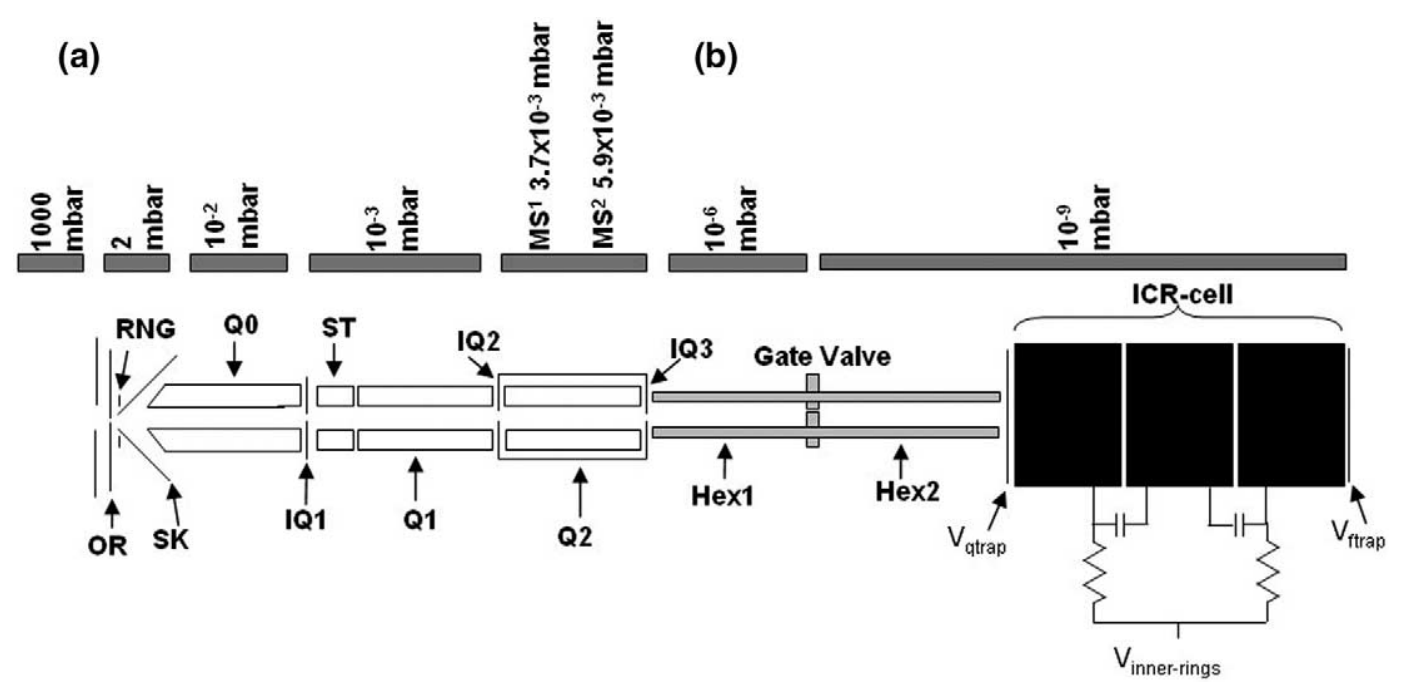

Figure 1. A schematic of the qQq- FTMS instrument (not to scale). Section (a) of the instrument was based on the API 365 triple quadrupole mass spectrometer: OR: orifice; RNG: focusing ring; SK: skimmer; Q0: RF only quadrupole, Q1: resolving quadrupole, Q2: LINAC collision cell. Section (b) is a custom-built system: Hex1 and Hex2: rf-only transfer hexapoles. The ion cyclotron resonance cell is a capacitatively coupled cylindrical cell divided into three axial segments. The pressures measured in the various sections of the instrument are shown on the bar above the figure.

can determine the total number of modifications on a protein by measuring the intact mass and comparing the measured and expected masses, and one can then localize the modification to a region or sometimes to a single amino acid residue by successively fragmenting the protein. The protein mass alone can sometimes be informative, especially when characterizing proteins from known open reading frames where a modification, splice variant or mutant form of the specified protein can be identified from the measured mass value. However, the protein mass alone is often insufficient to identify an unknown protein since PTMs and processing could change the predicted mass of the protein, or the predicted open reading frame (ORF) might be incorrect [25]. That said, a combination of the intact mass and partial protein sequence data derived from protein fragmentation can be very successful in protein identification [26].

High-resolution, accuracy, and sensitivity are clearly important for the unambiguous assignment of protein identity and PTM sites. In an effort to achieve these characteristics, a hybrid Fourier transform mass spectrometer was built in a collaborative effort by researchers at Boston University School of Medicine and MDS SCIEX. This qQq-FTICR system provided the flexibility of performing CAD in the RF collision cell (q2) or ECD or SORI-CAD in the ICR cell. The use of the mass resolving quadrupole (Q1) for precursor isolation provided improved speed and simplicity. These features enabled either detailed top-down or bottom-up approaches to be explored for protein analysis, resulting in a more complete characterization of proteins.

To explore the utility of this instrument for biological applications, two common biological challenges were chosen: the analysis of PTMs and top-down protein sequencing. For the former, protein phosphorylation was focused on as it is arguably one of the most common and important PTMs. Furthermore, the analysis of protein phosphorylation allowed exploration of the advantages of different features and fragmentation methods provided by this novel instrument as this post-translational modification is usually found in substoichiometric concentrations and the modification is sometimes labile. In addition, top-down sequencing on both commonly available standards and on biologically derived samples was explored to test the utility of this instrument for the analysis of whole proteins.

\section{Experimental}

Figure 1 is a diagram of the novel electrospray qQqFTICR instrument. The detailed instrument design was described elsewhere [27]. The front end construction is based on a commercial triple quadrupole (AB/MDS SCIEX API 365) with the third resolving quadrupole being replaced by the transfer hexapoles 1 and 2 and the ICR cell. The instrument employs a typical curtain-gas ion source design, a focusing rf-only quadrupole (Q0), a stubby quadrupole (ST) for improved ion transmission, followed by a resolving quadrupole (Q1), and a LINAC quadrupole trapping collision cell (Q2) [28-30]. The inter-quadrupole plates IQ1, IQ2, and IQ3 also provides conduction limits and can be used as trapping plates for the LINAC. Ions are then transmitted from the collision cell into the ICR cell using two rf-only hexapoles separated by a gate valve [31]. The home built ICR cell is a closed cylindrical cell similar to the Beu and Laude design [32] but with extra, external trapping plates.

The in-house built ESI qQq-FTMS uses a 7 Tesla actively shielded magnet (Cryomagnetics Inc., Oak 
Ridge, TN), and the ICR cell was controlled by the Ionspec (Irvine, CA) Omega data system. The qQq section instrument is controlled by an Apple Power PC and LC2Tune/MacDAD software (MDS SCIEX, Toronto, Canada) with the exception of IQ2 and IQ3 DACs, which are controlled by the Omega data system. An in-house built nanoelectrospray source was used for all experiments. The hexapoles, Q0 and Q2, were always operated in the rf-only mode. Nitrogen collision gas was always present in Q2 for both $\mathrm{MS}^{1}\left(3.7 \times 10^{-3}\right.$ mbar) and $\operatorname{MS}^{2}\left(5.9 \times 10^{-3}\right.$ mbar $)$ experiments to collisionally cool and focus the ions. The pressures reported were calculated from the measured pressure in the manifold. For $\mathrm{MS}^{1}$ experiments the collision energy was kept below $10 \mathrm{eV}$ to avoid fragmentation.

The instrument allowed several types of $\mathrm{MS}^{2}$ experiments to be performed. Ions could be isolated by transmission through Q1 in a mass filtering mode, or in the ICR cell by the conventional SWIFT method [33]. Fragmentation could be performed in Q2 by controlling the axial injection energy as in a triple quadrupole or QqTOF, or by using sustained off resonance irradiation (SORI)-CAD [34], electron capture dissociation (ECD) [3], or infra-red multi-photon dissociation (IRMPD) [35] in the ICR cell (IRMPD fragmentation was not performed in the experiments described here). Q2 CAD experiments were performed by increasing the DC voltages of the front end ion optic elements, which effectively raises the collision energy (typical collision energies used were $15-35 \mathrm{eV}$ ). Typical isolation windows for Q1 were 2 to $3 \mathrm{~m} / \mathrm{z}$ wide for $\mathrm{MS}^{2}$ experiments, to transmit the isotopic cluster. ECD experiments were performed in the ICR cell by irradiating trapped ions with low-energy electrons from the $6 \mathrm{~mm}$ diameter dispenser cathode (model STD200, Heatwave, Watsonville, CA), which was heated using $5 \mathrm{~V}$ at $1.2 \mathrm{~A}$ across the heating filament. The electron beam was directed into the ICR cell by changing the voltage bias on the cathode body for periods of 5-500 ms using a characteristic energy of $0.2 \mathrm{eV}$. Gas pulses were not used in general except for SORI-CAD or for the detection limit experiments described later. The total pulse duration for ECD experiments varied between $750 \mathrm{~ms}$ and $2 \mathrm{~s}$. The SORI CAD [34] experiments were carried out after isolating the species of interest using Q1. These experiments were performed by calculating the off resonant excitation frequency as described by Mirgorodskaya et al. for both single or multiple SORI events [36].

The presence of the Q2 collision cell facilitated fast $\mathrm{MS}^{1}$ and $\mathrm{MS}^{2}$ experiments. All MS ${ }^{1}$ experiments were performed using collision gas in Q2 and keeping collision energies low, to facilitate translational cooling of the ions so that use of pulse gas collisional cooling in the ICR cell was unnecessary. This method improved acquisition speed by at least 2 to $3 \mathrm{~s}$, as there was no need to evacuate the pulse gas from the ICR cell before detection. Thus, the precursor ions could be accumulated and fragmented independent of the detection of the fragment ions in the ICR cell. This geometry al- lowed the FT ICR mass measurements in an LC-compatible time scale. Furthermore, Q2 could be used to store and accumulate ions before transferring the ions into the ICR cell, and this increased the abundance of the precursor ions in the FTICR mass analyzer, thus effectively increasing the dynamic range [37].

Precursor ion selection in the resolving quadrupole Q1 allowed unit $\mathrm{m} / \mathrm{z}$ resolution and could be used to separate the species of interest from other ions or contaminants present. In conventional FTICR instruments, the ICR cell is used to isolate the precursor of interest using SWIFT [33]. However, SWIFT experiments can be limited in utility. Space charge effects and volume constraints in the cell restrict the initial number of ions in the cell so that the ions of interest in the cell are a subset of the ions initially present in the cell. Furthermore, SWIFT can sometimes radially excite ions, causing ion activation loss. With this hybrid instrument, selected ions of interest were isolated by Q1 and accumulated in Q2 before these species were transferred to the ICR cell. Hence, species found in substoichiometric concentrations could be analyzed with ease since the ICR cell was filled only with ions of interest, effectively increasing the dynamic range. This capability has been shown previously with custom built FTMS instruments [38-40], but this instrument was unique in coupling the well-developed MDS/SCIEX front end capabilities with FTMS. A more detailed description of the geometry and construction of this novel hybrid mass spectrometer has been presented [27] and will be published elsewhere. Electronic noise signals were evident in many of the spectra and are marked with an asterisk. These signals were clearly distinguishable from real ions as they did not exhibit an isotopic signature. While these signals have not been completely eliminated, their intensities have been substantially reduced by improved shielding and removal of ground loops from the system.

All materials were purchased from Sigma Chemicals (St. Louis, MO) unless specified otherwise. MilliQ water (Millipore, Bedford, MA) was used during the preparation of biological samples before gel separation. NuPage Novex gels, MOPS buffer, and colloidal Coomassie stain, used for protein separation and visualization, were purchased from Invitrogen (Carlsbad, CA). Solvents used for mass spectrometric analysis and gel band preparation such as methanol, water and acetonitrile were HPLC grade and were obtained from Burdick and Jackson (Muskegon, MI). Peptides used for testing the sensitivity of the instrument were made, purified, and quantified by Cell Signaling Technology (Beverly, MA). Digests were performed according to Shevchenko et al. [41]. Peptides and digests were desalted using stage tips equipped with Empore Disk C18 (3M, Minneapolis, MN) [42]. Proteins were desalted using R1/50 POROS material (Applied Biosystems, Framingham, MA) as described previously by Gobom et al. [43]. All peptides and digested samples were analyzed using a spray solution of $60 \%$ methanol in $5 \%$ formic acid. Needles 


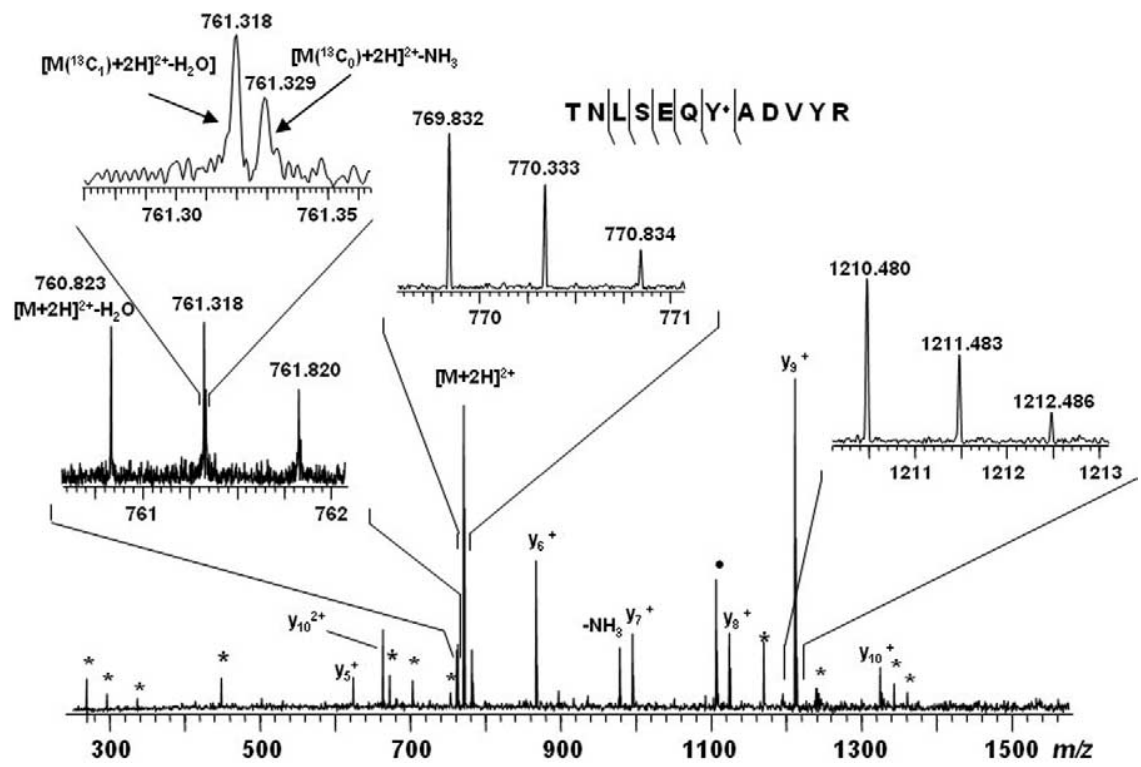

Figure 2. A product ion spectrum of the tyrosine phosphorylated peptide TNLSEQY ADVYR is shown. The resolving power of the ICR mass analyzer is demonstrated by this spectrum that displays a fragment ion at $m / z 761.761$ that has an atypical isotope distribution-a result from overlap of the [M $\left.+2 \mathrm{H}-\mathrm{H}_{2} \mathrm{O}\right]^{2+}$ and the $\left[\mathrm{M}+2 \mathrm{H}-\mathrm{NH}_{3}\right]^{2+}$ species. (Filled circle: $-\mathrm{H}_{2} \mathrm{O}$; asterisk: electronic noise).

were pulled using a heated filament micropipette puller (P-97, Sutter Instrument, Novato, CA).

UbCH10 was cloned into the Eco RI, Xho 1 sites of a pET28b vector (Novagen) using a nonexpression host, Novablue. The plasmid was amplified and purified and used to transform competent E. coli BL21 (DE3) cells. Transformed cells were selected using kanamycin sulfate $30 \mathrm{ug} / \mathrm{mL}$ (OmniPur, Gibbstown NJ). A fresh inoculum of these transformed cells was grown at $37^{\circ} \mathrm{C}$ until an o.d. of 0.6 absorption units was reached. Isopropyl- $\beta$-D-thiogalactopyranoside (IPTG) was then added to a final concentration of $0.4 \mathrm{mM}$ and incubated for 2 to $3 \mathrm{~h}$. The cells were then harvested at $4{ }^{\circ} \mathrm{C}$, washed, and lysed. The His-tagged protein was purified from lysate by passing it over a Ni-NTA column (Qiagen, Valencia, CA). An aliquot of this protein preparation was then desalted using a column consisting of $30 \mathrm{~nL}$ of POROS R1 reversed-phase material (Applied ${ }^{\circ}$ Biosystems) ${ }^{\circ}$ as ${ }^{\circ}$ described $^{\circ}$ by $^{\circ} \mathrm{Gobom}^{\circ} \mathrm{et}^{\circ}{ }^{\circ} 1 .{ }^{\circ}$ [43]. Samples were eluted directly into a nanoelectrospray needle. The top-down experiment was performed by isolating the selected ion using Q1 and by performing Q2 CAD on the ion, at a collision energy of $\sim 23 \mathrm{eV}$.

\section{Results and Discussion}

One of the most important characteristics of FTICR MS is the high mass resolving power (routinely $>10^{5}$ and occasionally $\left.10^{6}\right)^{\circ}[44]$. The $^{\circ}$ advantages ${ }^{\circ}$ provided ${ }^{\circ}$ by ${ }^{\circ}$ this feature were evident in the details of the Q2 CAD (using conditions cited in the Experimental section) fragment ion spectrum of the tyrosine-phosphorylated peptide TNLSEQ(pY)ADVYR ${ }^{\circ}\left(\right.$ see $^{\circ}$ Figure $\left.^{\circ} 2\right){ }^{\circ}{ }^{\circ}$ For $^{\circ}$ instance, ${ }^{\circ}$ the doubly charged fragment ion at $m / z 760.832$ showed an atypical isotope distribution (in all the figures the phosphate moiety is denoted by a filled diamond $\bullet$ ). Further analysis revealed the overlap of the $[\mathrm{M}+2 \mathrm{H}-$ $\mathrm{H}_{2} \mathrm{O}^{2+}$ and the $\left[\mathrm{M}+2 \mathrm{H}-\mathrm{NH}_{3}\right]^{2+}$ species. Although the ${ }^{13} \mathrm{C}_{1}$ isotope peak of the former species was nominally isobaric with respect to the ${ }^{13} \mathrm{C}_{0}$ species of the latter, the exact masses differed by $0.01 \mathrm{Da}$ and were easily resolved by this instrument, even for doubly charged ions at $\mathrm{m} / \mathrm{z} 760$ by this instrument. High resolving power $(100,000 \mathrm{FWHM})$ and mass accuracy of $\sim 1 \mathrm{ppm}$ could be readily achieved when an internal calibration of the spectra was performed (in this case the $\mathrm{y}_{10}{ }^{+}$and $\mathrm{y}_{10}{ }^{2+}$ ions were used to internally calibrate the spectrum). Although in typical $\mathrm{MS}^{2}$ spectra resolving the $-\mathrm{H}_{2} \mathrm{O} /-\mathrm{NH}_{3}$ species is not biologically interesting, it is important to note that this mass shift is the same shift observed on deamidation of asparagine or glutamine ${ }^{\circ}$ residues ${ }^{\circ}[45]^{\circ}{ }^{\circ}$ this ${ }^{\circ}$ post-translational ${ }^{\circ}$ modification is linked to protein aging, protein folding disorders, and protein degradation.

To test the achievable sensitivity of this instrument, a dilution series of the phosphopeptide EPGPIAPSTNS(pS)PVLK [leucine labeled ${ }^{13} \mathrm{C}_{6}(98 \%)$ and ${ }^{15} \mathrm{~N}_{1}(98 \%)$ ] that had been quantified using amino acid analysis was performed..$^{\circ}$ Nanoelectrospray ${ }^{\circ}\left[46,{ }^{\circ} 47\right]^{\circ}$ was $^{\circ}$ used $^{\circ}$ to ${ }^{\circ}$ test the limits of detection. Since separate needles were used for each experiment, sample cross-over problems were avoided. ${ }^{\circ}$ Figure ${ }^{\circ} 3 \mathrm{a},{ }^{\circ} \mathrm{b},{ }^{\circ}$ and ${ }^{\circ} \mathrm{c}^{\circ}$ show $^{\circ}$ mass $^{\circ}$ spectra $^{\circ}$ summing 10 scans for $100 \mathrm{fmol} / \mu \mathrm{L}, 10 \mathrm{fmol} / \mu \mathrm{L}$, and 1 $\mathrm{fmol} / \mu \mathrm{L}$, respectively. Q2 accumulation time of $0.5 \mathrm{~s}$ was used for these experiments without any collisional cooling in the ICR cell. Even the $1 \mathrm{fmol} / \mu \mathrm{L}$ sample analyzed by nanoelectrospray ionization provided a signal-to-noise ratio $(\mathrm{S} / \mathrm{N})$ of more than 20 . The total 

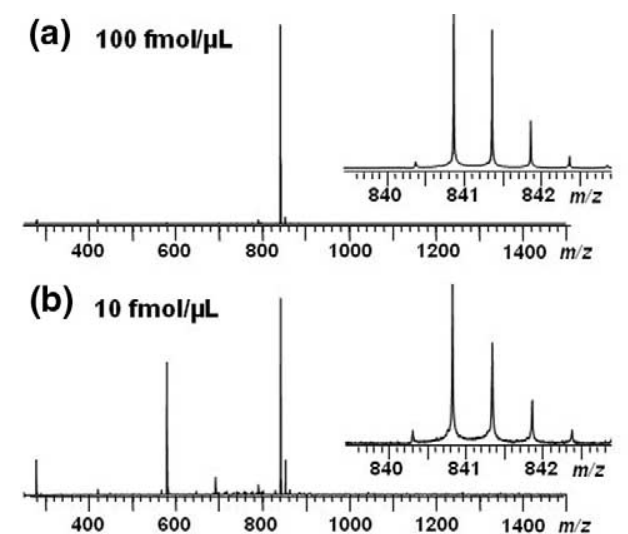

(c) $1 \mathrm{fmol} / \mathrm{\mu L}$

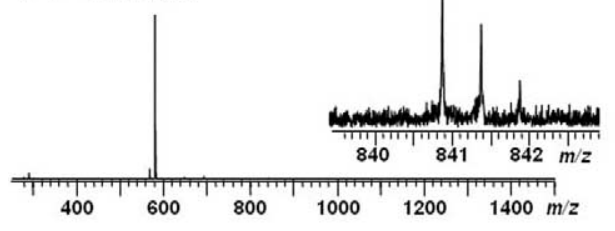

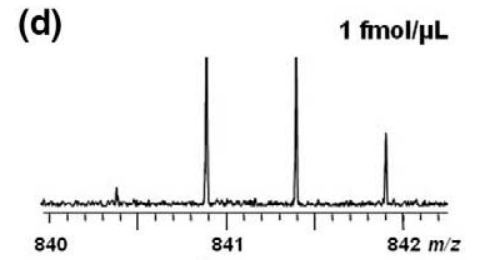
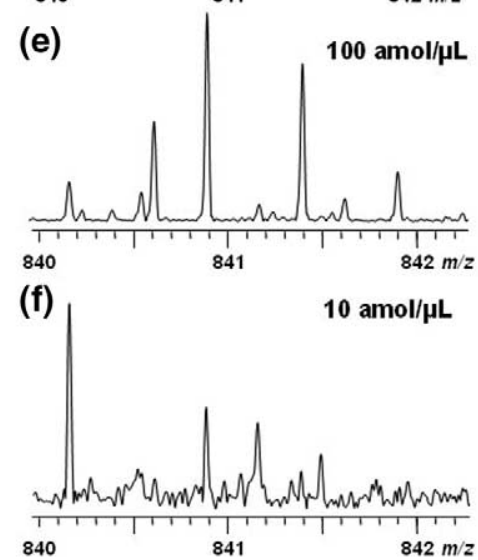

Figure 3. (a) (b) (c) show nanoelectrospray ionization spectra for a dilution series of the synthetic phosphopeptide EPGPIAPSTNSS PVLK. These spectra were acquired without Q1 isolation, with a Q2 accumulation time of $0.5 \mathrm{~s}$ and without collisional cooling in the ICR cell. (d) and (f) show the spectra of a dilution series extending to even lower concentrations; these spectra were acquired with Q1 isolation, with Q2 accumulation time of $1.5 \mathrm{~s}$, and collisional cooling in the ICR cell.

acquisition time required for each of these spectra was $1 \mathrm{~s}$, a value well within a time scale compatible with LC/MS experiments.

To improve the detection limit, the Q2 accumulation time was increased to $1.5 \mathrm{~s}$, a $2 \mathrm{~s}$ collisional cooling and pump down delay following a 2-ms nitrogen gas pulse (resulting peak pressure in ICR cell $\sim 6.6 \times 10^{-7} \mathrm{mbar}$ ) in the ICR cell and a $2 \mathrm{~s}$ detection period were used (pressure in ICR cell $\sim 3 \times 10^{-10} \mathrm{mbar}$ ), bringing the total cycle time to $5.5 \mathrm{~s}$. The resulting spectra summing

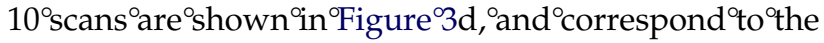
analysis of solutions containing $1 \mathrm{fmol} / \mu \mathrm{L}, 100$ $\mathrm{amol} / \mu \mathrm{L}$ and $10 \mathrm{amol} / \mu \mathrm{L}$ of the same phosphopeptide, respectively. The $\mathrm{S} / \mathrm{N}$ of $\sim 3$ was achieved at $10 \mathrm{amol} /$ $\mu \mathrm{L}$, indicating the approximate detection limits of this instrument. Although $5.5 \mathrm{~s}$ per cycle is not compatible with "discovery-type" LC/MS experiments, it is sufficiently short to perform LC/MS experiments in a directed fashion: for example, the targeted analysis of specific peptides.

To test the application of the instrument to complex mixtures, $100 \mathrm{fmol}$ of a tryptic $\beta$-casein digest was analyzed ${ }^{\circ}$ by $^{\circ}$ nanoelectrospray ${ }^{\circ}$ ionization. ${ }^{\circ}$ Figure $^{\circ} 4 \mathrm{a}$ shows the mass spectrum of the digest using a pulse sequence with a $1 \mathrm{~s}$ total duration time. Using Q1 as a mass filter, a clean isolation of precursors was achieved, as demonstrated in Panel $\mathrm{b}$ featuring the unmodified peptide DMPQAFLLYQEPVLGPVR. The asterisks indicate electronic noise in the spectrum, which are also evident in the MS ${ }^{2}$ spectrum. Panel c shows the Q2 CAD product ion spectrum of this isolated peptide, still using a pulse sequence with a $1 \mathrm{~s}$ duration. The isola- tion, fragmentation, and cooling of ions before transfer and detection in the ICR cell allowed for fast acquisition, so that low abundance species in complex mixtures could be analyzed in short periods of time using discrete nanoelectrospray or LC/MS. Q1 was capable of isolating a single isotopic peak of the doubly charged peptide ${ }^{\circ} a^{\circ} \mathrm{m} / z$ 840.9195. ${ }^{\circ}{ }^{\circ}{ }^{\circ}$ Figure $^{\circ} 5 b^{\circ},{ }^{\circ} a^{\circ}$ single ${ }^{\circ}$ isotopic ion species of the ${ }^{13} \mathrm{C}$ and ${ }^{15} \mathrm{~N}$ labeled peptide (leucine labeled ${ }^{13} \mathrm{C}_{6}$ and ${ }^{15} \mathrm{~N}_{1}$ ) EPGPIAPSTNS(pS)PVLK was isolated in a direct injection nanospray experiment at 10 $\mathrm{fmol} / \mu \mathrm{L}$. This peptide is labeled with both the ${ }^{13} \mathrm{C}$ and ${ }^{15} \mathrm{~N}$ species, each being enriched to $98 \%$ and, thus, signal for a somewhat under-enriched species is evident at $\mathrm{m} / \mathrm{z} 840.4190$. Since it can be seen that the most abundant isotopic peak in this doubly charged cluster was isolated from both its isotopic neighbors, clearly the isolation window was less than $1 \mathrm{~m} / \mathrm{z}$ FWHM. A 4 -fold loss in signal intensity of the ion species was observed, when using such a narrow window of isolation, as is commonly observed for quadrupole mass filters. This loss could be compensated by increasing the accumulation time if necessary. The ability for unit $\mathrm{m} / \mathrm{z}$ isolation is particularly important in top-down protein studies (see below), where the multiply charged protein precursor ion may fall within only one $\mathrm{m} / \mathrm{z}$ unit of ions due to substantial contaminants, for example, sodiumadducted species, sequence variants, or post-translationally modified precursors.

The same $\beta$-casein digest was diluted to $20 \mathrm{fmol} / \mu \mathrm{L}$ for ${ }^{\circ}$ further ${ }^{\circ}$ experiments ${ }^{\circ}$ (Figure $\left.{ }^{\circ} 6 \mathrm{a}\right) .{ }^{\circ} \mathrm{A}^{\circ}$ doubly $^{\circ}$ charged peptide ion was observed at $\mathrm{m} / \mathrm{z} 1032.417$ and corresponded to the singly phosphorylated peptide $\mathrm{FQ}(\mathrm{pS}) \mathrm{E}-$ 


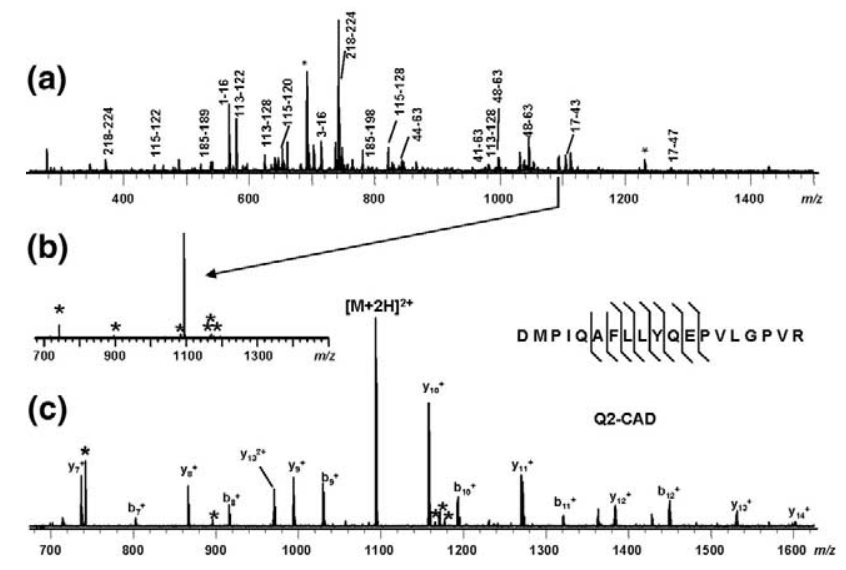

Figure 4. (a) The $\mathrm{MS}^{1}$ mass spectrum obtained for $100 \mathrm{fmol}$ of a tryptic $\beta$-casein digest using a total pulse sequence time of $1 \mathrm{~s}$ (an LCMS-compatible time scale). The arrow points to the ion at $\mathrm{m} / \mathrm{z}$ 1093.587, corresponding to peptide 199-217. (b) Q1 isolation of the peptide 199-217 from a tryptic digest of $\beta$-casein. (c) A Q2 CAD product ion spectrum of the peptide 199-217 from a tryptic $\beta$-casein digest, which identified the peptide and protein unambiguously. (Asterisk: electronic noise).

EQQQTEDELQDK. ${ }^{\circ} \mathrm{To}^{\circ}$ evaluate ${ }^{\circ}$ the ${ }^{\circ}$ advantages ${ }^{\circ}$ of $^{\circ}$ performing peptide fragmentation in Q2 outside the FTICR cell versus SORI-CAD inside the cell, this phosphopep-

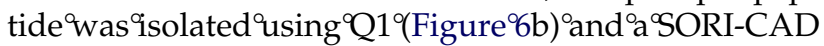
experiment $\left(12 \mathrm{~V}_{\mathrm{bp}}{ }^{\circ}-1.5 \%{ }^{\circ} \Delta \omega_{\mathrm{c}}\right)^{\circ}$ was $^{\circ}$ performed ${ }^{\circ}$ (Figure 6c). ${ }^{\circ} \mathrm{SORI}^{\circ} \mathrm{CAD}^{\circ}$ is $^{\circ}$ often ${ }^{\circ}$ useful ${ }^{\circ}$ for $^{\circ}$ unmodified $^{\circ}$ peptides or modified peptides with stable modifications, as this type of fragmentation produces enough sequence information to identify the peptide of interest and locate the site of the nonlabile modification. However, limitations become obvious in the case of labile modifications such as serine and threonine phosphorylation. In the particular case of the peptide $\mathrm{FQ(pS)EEQQQTEDELQDK}$ where the $\mathrm{O}$-substituted phosphate is very labile, a phosphoric acid $\left(\mathrm{H}_{3} \mathrm{PO}_{4}\right)$ equivalent was readily lost from the serine residue, leaving a dehydroalanine residue..$^{\circ}$ This $^{\circ}$ is ${ }^{\circ}$ indicated ${ }^{\circ}$ in $^{\circ}$ Figure $^{\circ} 6 c^{\circ}$ by $^{\circ}$ the ${ }^{\circ}$ complete conversion of the phosphorylated precursor to the dephosphorylated species $\left[\mathrm{M}+2 \mathrm{H}-\mathrm{H}_{3} \mathrm{PO}_{4}\right]^{2+}$ after the SORI CAD event. No further sequence-revealing fragment ions were observable in the product ion spectrum. To generate information pertaining to the sequence and localization of the phosphorylation site, additional SORI CAD experiments are generally necessary. This is time consuming, as several collision gas pulses in the ICR cell are necessary, with the concomitant evacuation of the ICR cell before detection of ions. In contrast, the fragmentation spectra obtained from the Q2 generally required less than $1 \mathrm{~s}$ and significant sequence coverage could be obtained from Q2 CAD spectra, since many collisions take place during fragmentation and trapping in the collision cell. Thus, even after the labile $\mathrm{H}_{3} \mathrm{PO}_{4}$ was lost, the resulting fragments underwent further collisions and fragmentations, with the result that sequence information relating to the localization of the dehydroalanine residue and, hence, the prior phosphorylation site could be unambiguously determined, ${ }^{\circ}$ as $^{\circ}$ per $^{\circ}$ Figure $^{\circ} 6 \mathrm{~d} .{ }^{\circ}$ This $^{\circ}$ also ${ }^{\circ}$ applies ${ }^{\circ}$ to ${ }^{\circ}$ the threonine phosphorylated peptides which formed a dehydroaminobutyric acid residue on losing a phosphoric acid equivalent. The Q2 CAD spectrum shown in Panel D also displayed several peptide fragments that have the phosphorylation site still intact. This favorable situation may be due to the use of collision energies of only $15 \mathrm{eV}$.

To show that this type of experiment could be performed on LC/MS time scales at low nanomolar concentrations, a $10 \mathrm{fmol} / \mu$ l solution of a phosphopep-

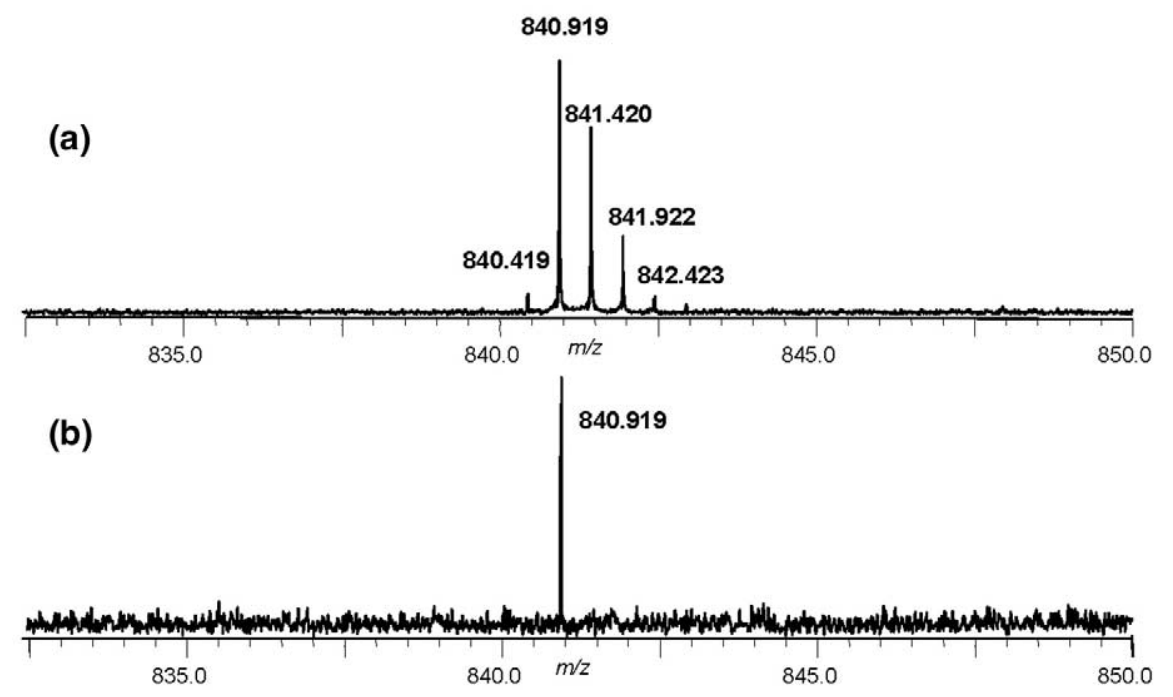

Figure 5. (a) The $M S^{1}$ mass spectrum obtained for $10 \mathrm{fmol} / \mu \mathrm{L}$ solution of the ${ }^{13} \mathrm{C}_{6},{ }^{15} \mathrm{~N}_{1}$ leucinelabeled synthetic phosphopeptide EPGPIAPSTNSS PVLK. As the isotopic purity of both the ${ }^{13} \mathrm{C}$ and ${ }^{15} \mathrm{~N}$ species is only $98 \%$, a signal at $m / z 840.419$ is observed for the incompletely labeled peptide. (b) Q1 isolation of the isotopic signal at $m / z 840.920$. 

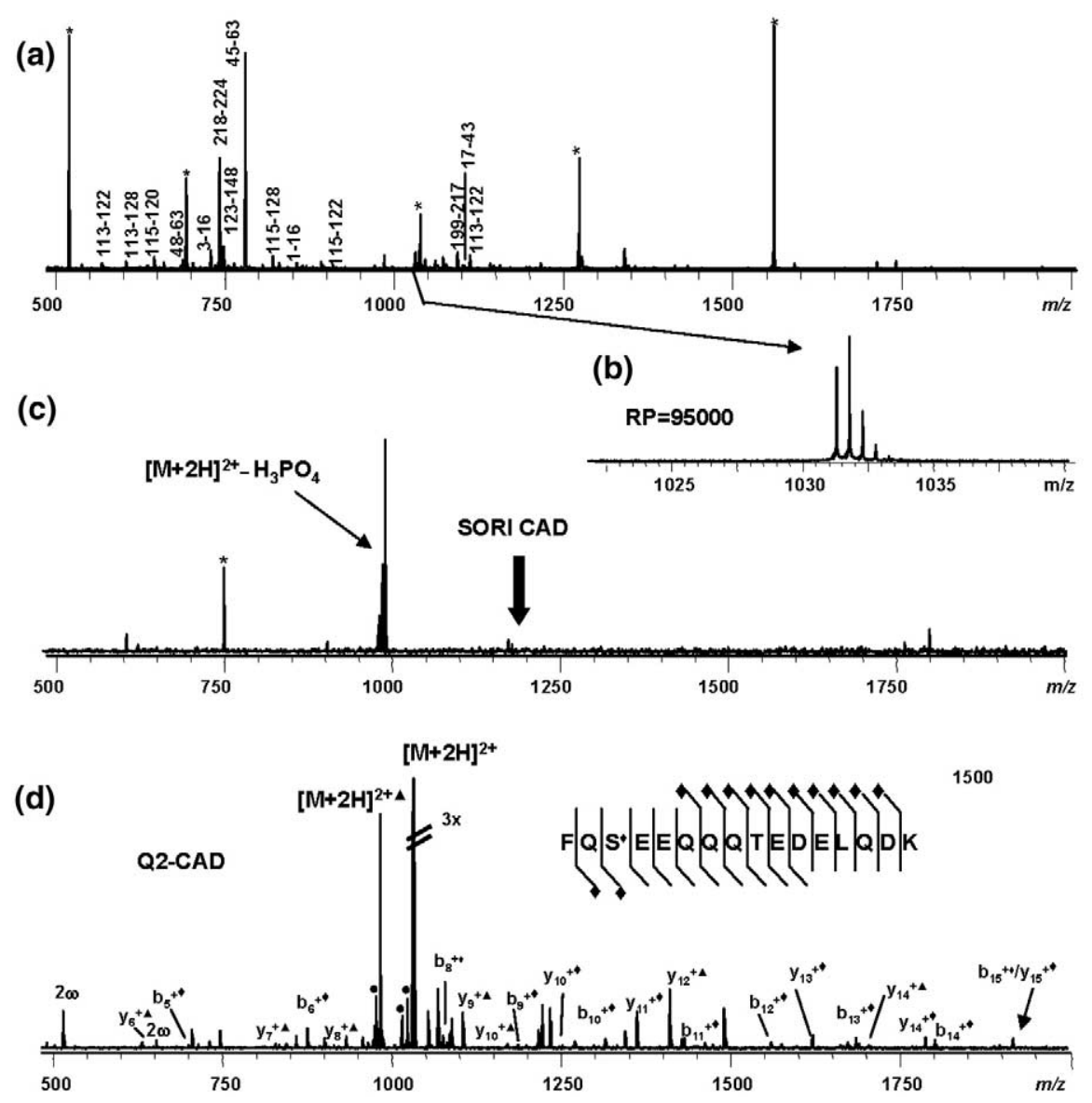

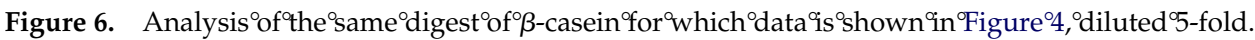
(a) The $\mathrm{MS}^{1}$ mass spectrum. (b) Isolation of the doubly charged peptide at $\mathrm{m} / \mathrm{z} 1032.417$ FQS EEQQQTEDELQDK (the arrow indicates the selection of this species from the MS ${ }^{1}$ spectrum). (c) SORI CAD MS2 spectrum. The SORI-CAD event (arrow) gave rise to the predominant neutral loss species and very few other fragments, with the result that it is impossible to localize the phosphorylation. (d) Q2 CAD $\mathrm{MS}^{2}$ spectrum containing sequence revealing fragments which allow the unambiguous identification of the peptide and localization of the phosphorylation site. (Filled diamond: fragments with phosphate intact; filled triangle: $-\mathrm{H}_{3} \mathrm{PO}_{4}$; filled circle: $-\mathrm{H}_{2} \mathrm{O}$; asterisk: electronic noise).

tide EGPIAPSTNS(pS)PVLK [leucine labeled ${ }^{13} \mathrm{C}_{6}(98 \%)$ and $\left.{ }^{15} \mathrm{~N}_{1}(98 \%)\right]^{\circ}$ was ${ }^{\circ}$ analyzed. ${ }^{\circ}$ Figure ${ }^{\circ} 7 \mathrm{a}^{\circ}$ shows ${ }^{\circ}$ an ${ }^{\circ} \mathrm{MS}$ spectrum obtained using a total cycle time of $1 \mathrm{~s}$ with an external accumulation time of $0.5 \mathrm{~s}$. The low chemical noise even in the MS spectrum is noteworthy (see Figure 7a). Figure $7 \mathrm{~b}$ shows a product ion spectrum for the same concentration of phosphopeptide with a $1.5 \mathrm{~s}$ accumulation time in Q2 and a total acquisition time of 2 s. Remarkably, the Q2 CAD MS ${ }^{2}$ spectra for this particular peptide exhibited many fragment ions bearing the intact allyl phosphoester and, thus, allowed unambiguous identification of the phosphorylation site. This phenomenon has also been observed for this peptide in a 3-D

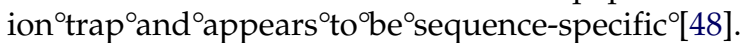

The instrument was equipped with an electron gun $^{\circ}[49]^{\circ}$, allowing $^{\circ}$ electron-ion ${ }^{\circ}$ reactions $^{\circ}$ such $^{\circ}$ as electron ${ }^{\circ}$ capture $^{\circ}$ dissociation $^{\circ}(\mathrm{ECD})^{\circ}[3]^{\circ}{ }^{\circ}$ and ${ }^{\circ}$ electron detachment ${ }^{\circ}$ dissociation $^{\circ} \mathrm{EDD}^{\circ}[50]^{\circ}$ to $^{\circ}$ be $^{\circ}$ used $^{\circ}$ to fragment peptides. ECD has been found to be partic- ularly useful for phosphopeptide analysis because the ${ }^{\circ}$ ally $l^{\circ}$ phosphoester ${ }^{\circ}$ remains $^{\circ}$ intact $^{\circ}\left[8,{ }^{\circ} 9\right]^{\circ} .^{\circ} \mathrm{To}^{\circ}$ test this capability on the new hybrid instrument, the phosphopeptide LRL(pS)PSPTSQR was spiked into a bovine serum albumin digest at an equimolar concentration. ${ }^{\circ}$ Figure $^{\circ} 8 \mathrm{a}^{\circ}$ shows $^{\circ}$ the ${ }^{\circ}$ mass $^{\circ}$ spectrum $^{\circ}$ of ${ }^{\circ}$ the complex mixture with the phosphopeptide peak marked by a dotted arrow. Reported masses were generated following internal calibration based on trypsin autolysis peptides. Panel B shows the mass spectrum of the phosphopeptide, $[\mathrm{M}+\mathrm{H}]^{2+} \mathrm{m} / \mathrm{z}$ 661.3348, isolated by Q1. This isolated ion was subsequently subjected to ECD and the spectrum acquired $^{\circ}$ from $^{\circ}$ this ${ }^{\circ}$ experiment ${ }^{\circ}$ is ${ }^{\circ}$ shown $^{\circ}$ in ${ }^{\circ}$ Figure $^{\circ} 8 \mathrm{c}$. Because the bond to be broken is located in a ring, ECD fragmentation does not produce $\mathrm{N}$-terminal fragment ions resulting from cleavage within proline residues. By taking into account the fact that several proline residues were present in this peptide, the 


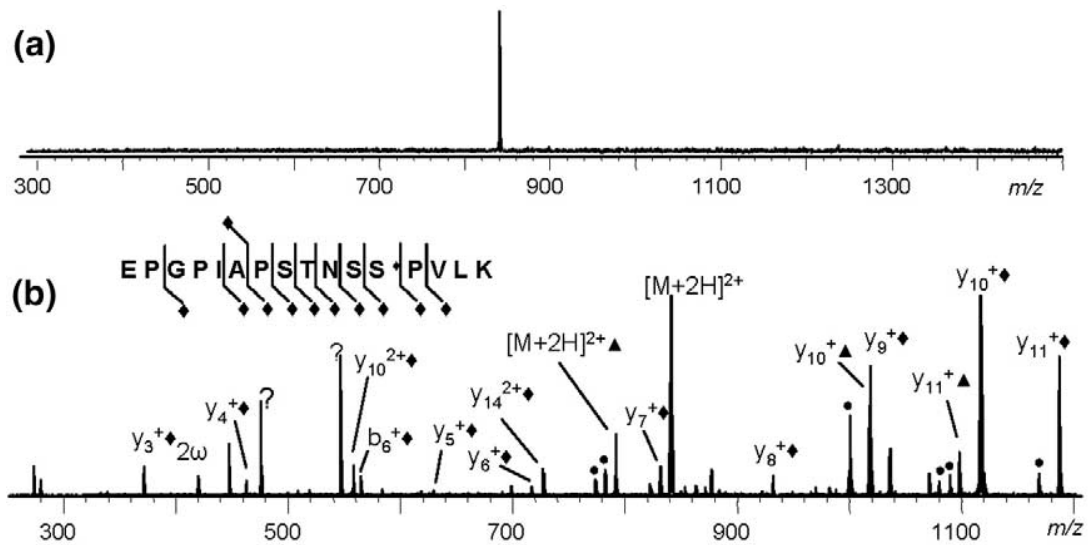

Figure 7. (a) To demonstrate the sensitivity of the instrument in $\mathrm{MS}^{1}$ and $\mathrm{MS}^{2}$ modes, $10 \mathrm{fmol}$ of the phosphopeptide EPGPIAPSTNSS PVLK was analyzed using a 1-s pulse sequence including $0.5 \mathrm{~s}$ of external accumulation. (b) A product spectrum was acquired for the same concentration of peptide using $15 \mathrm{eV}$ collision energy with a 1.5-s accumulation time in Q2, for a total pulse sequence duration of $2 \mathrm{~s}$. Most of the fragment ions seen in this spectrum correspond to fragment ions with the phosphate group still attached. (Filled diamond: fragments with phosphate intact; filled triangle: $-\mathrm{H}_{3} \mathrm{PO}_{4}$; filled circle: $-\mathrm{H}_{2} \mathrm{O}$; asterisk: electronic noise).

phosphorylation site could be localized on the basis of the observed $\mathrm{c}$ and $\mathrm{z}$ fragment ions.

Another promising application of FTICR MS is the ability to perform top-down protein analysis, i.e., the fragmentation ${ }^{\circ}$ of $^{\circ}$ intact $^{\circ}$ proteins $^{\circ}[51]^{\circ}{ }^{\circ}$ The $^{\circ}$ ability $^{\circ}$ to ${ }^{\circ}$ start $\mathrm{MS}^{\mathrm{n}}$ analysis with the intact protein, by definition, yields $100 \%$ sequence coverage, enabling the complete characterization of the protein and any associated post-translational

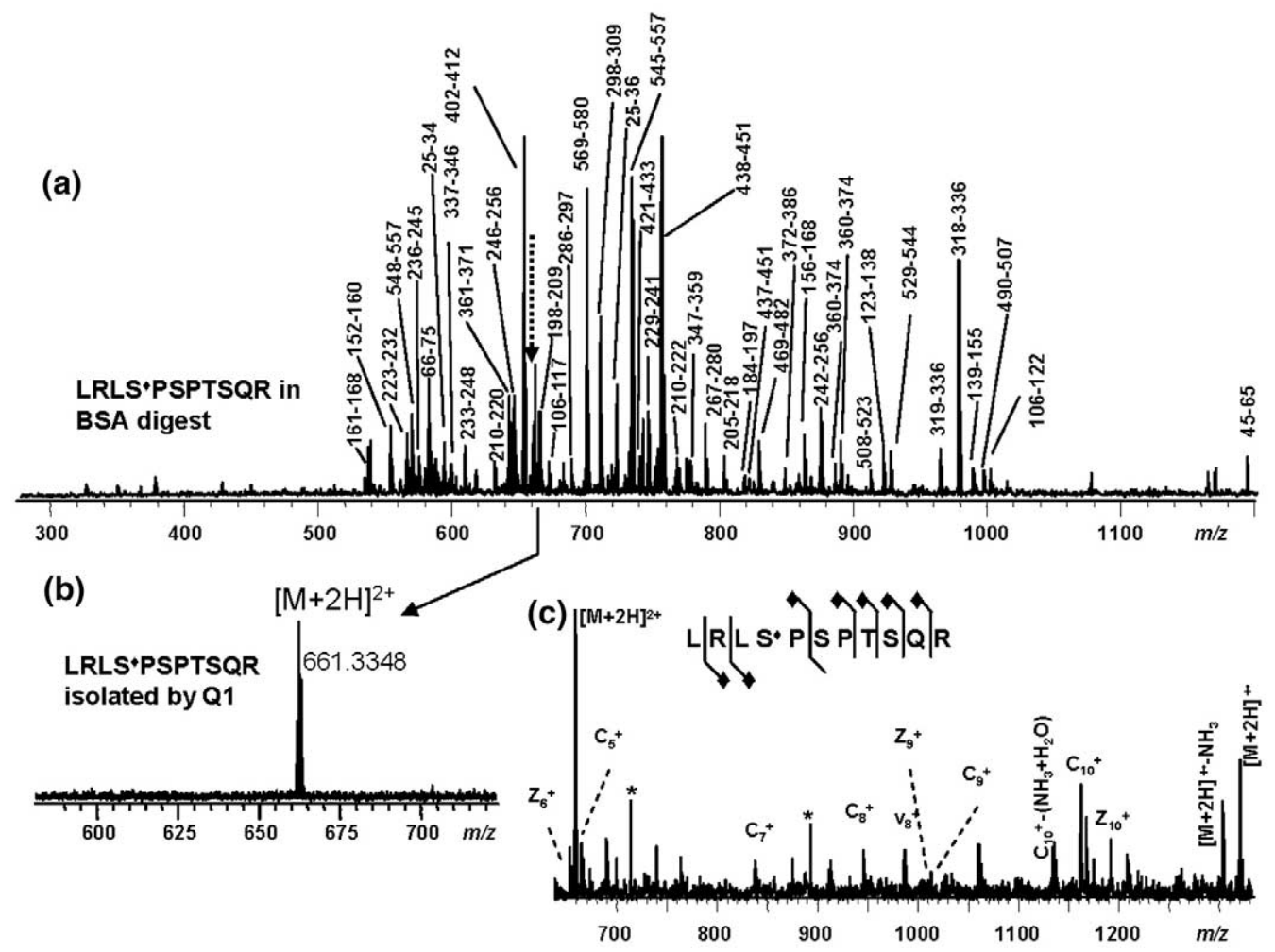

Figure 8. A BSA digest was spiked with a phosphopeptide in an equimolar ratio $(1 \mathrm{pmol} / \mu \mathrm{L})$. (a) The MS ${ }^{1}$ spectrum of this mixture. The dotted arrow indicates the spiked phosphopeptide. (b) Clean isolation of the phosphopeptide from the complex mixture using the resolving quadrupole Q1; this isolated species was then subjected to ECD. (c) The ECD spectrum of the isolated phosphopeptide. This spectrum provides enough information to localize the phosphorylation site. All fragment ions have the intact phosphate moiety. (Filled diamond: fragments with phosphate intact; filled triangle: $-\mathrm{H}_{3} \mathrm{PO}_{4}$; filled circle: $-\mathrm{H}_{2} \mathrm{O}$; asterisk: electronic noise). 
Ubiquitin (10+)

top-down using Q2-CAD

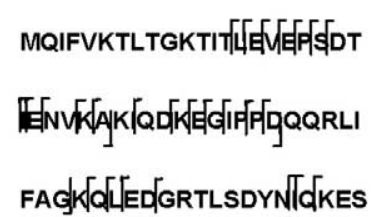

FTLHLVLRLRGG modifications. This is of paramount importance when carrying out phosphopeptide mapping studies. Often a protein is isolated under two different conditions (e.g., at different time points in the cell cycle) and several phosphorylation sites are mapped using one or two enzymes. However, unless $100 \%$ sequence coverage is obtained, one cannot be sure that the most biologically interesting sites have been found. With a top-down approach, the accurate intact mass of the protein provides information about the number of modifications on the protein, the locations of which can then be determined by fragmenting the protein [52]. ${ }^{\circ}$ For $^{\circ}$ top-down ${ }^{\circ}$ experiments ${ }^{\circ}$ to ${ }^{\circ}$ be $^{\circ}$ successful, ${ }^{\circ}$ two prerequisites have to be met: (1) the intact protein has to be cleaved as efficiently as possible, and (2) high-resolution/high accuracy data are required to unambiguously measure the mass of the numerous fragment ions generated and derive sequence information. Several of the fragments produced by CAD are rather large and highly charged, requiring high-resolution and high mass accuracy to identify the charge states and determine the identity of the fragment ions. While top-down tandem mass spectrometry experiments have been demonstrated with some success on quadrupole time-of-flight (qTOF) instruments ${ }^{\circ}[53-55],{ }^{\circ}$ many $^{\circ}$ of ${ }^{\circ}$ the ${ }^{\circ}$ protein ${ }^{\circ}$ fragments ${ }^{\circ}$ were $>15 \mathrm{kDa}$, thus requiring resolving power in excess of 20,000 . Only an FTICR instrument with its high resolving power $\left(>10^{5}\right)$ enables accurate assignments of charge state and mass both for MS and MS ${ }^{2}$ top-down experiments when the fragment ions are of such high mass. This approach, ${ }^{\circ}$ introduced ${ }^{\circ}$ by $^{\circ} \mathrm{McLafferty}^{\circ}$ and $^{\circ}{ }^{\circ}$ coworkers ${ }^{\circ}[24$, $51]^{\circ}$ is $^{\circ}$ proving ${ }^{\circ}$ to $^{\circ} \mathrm{be}^{\circ}$ useful ${ }^{\circ}$ for ${ }^{\circ}$ the $e^{\circ}$ application ${ }^{\circ}$ of biologically relevant samples, as shown by Kelleher and cowork$\operatorname{ers}^{\circ}\left[56,{ }^{\circ} 57\right] .{ }^{\circ}$ The $^{\circ}$ top-down ${ }^{\circ}$ approach ${ }^{\circ}$ has $^{\circ}$ been $^{\circ}$ further developed ${ }^{\circ}$ in $^{\circ}$ terms ${ }^{\circ}$ of ${ }^{\circ}$ software $\left.\left[58^{\circ}-80\right]\right]^{\circ}$ and ${ }^{\circ}$ the ${ }^{\circ}$ refinement of instrumentation for this purpose has recently been ${ }^{\circ}$ escribed $[61]$.

For protein identification purposes and for initial characterization or screening, it is frequently unnecessary to perform extensive top-down analysis. It is often sufficient to obtain a short sequence tag from abundant fragment ions and the accurate mass of the parent ion to determine ${ }^{\circ}$ identity $[26]$. Thus, $^{\circ}$ quick $^{\circ}$ experiments ${ }^{\circ}$ in $^{\circ}$ the order of 1 to $5 \mathrm{~s}$ may be sufficient to obtain the relevant spectra for the generation of a sequence tag. Ubiquitin is a well known standard used to test the performance of instruments for top-down experiments and, thus, it was chosen as an example to show the efficacy of Q2 CAD for partial-sequence characterization of proteins. This approach was shown using ubiquitin $(1 \mathrm{pmol} / \mu \mathrm{L})$ as a model $^{\circ}$ protein $^{\circ}$ and ${ }^{\circ}$ the ${ }^{\circ}$ spectrum ${ }^{\circ}$ is ${ }^{\circ}$ presented ${ }^{\circ}{ }^{\circ}{ }^{\circ}$ Figure 9. The ${ }^{\circ} \mathrm{MS} / \mathrm{MS}^{\circ}$ spectrum $^{\circ}$ was $^{\circ}$ obtained ${ }^{\circ}$ from ${ }^{\circ}{ }^{\circ}$ single ${ }^{\circ} 2$ CAD experiment without any effort being made to maximize the number of cleavages. The spectrum showed 30 cleavages for this protein, allowing construction of an excellent sequence tag.

Having tested the top-down approach with ubiquitin, it was important to apply these methods to proteins isolated from biologically derived samples, in 


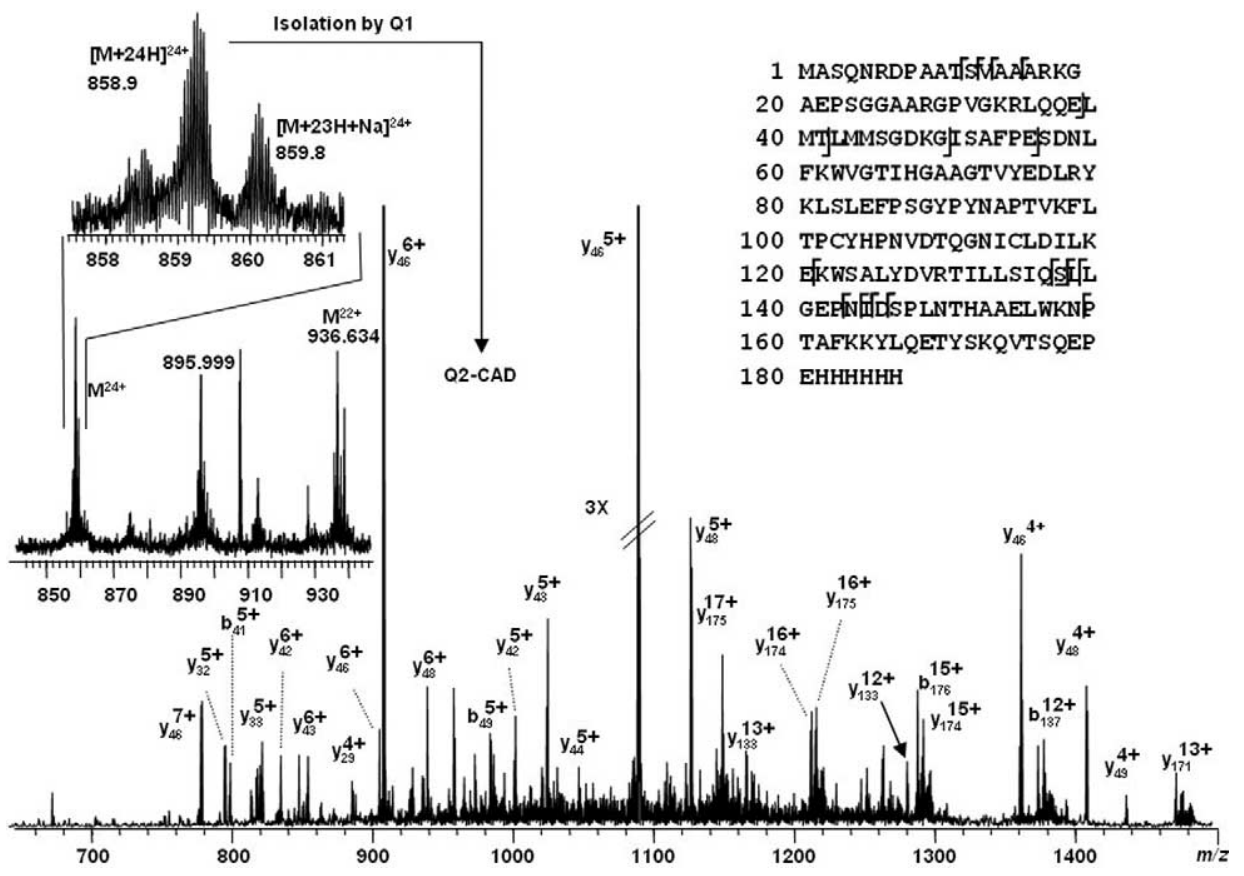

Figure 10. The human recombinant protein $\mathrm{UbCH} 10$ was subjected to top-down sequencing and this allowed the unambiguous verification of cloning sites and determination of the nature of the protein, including the His tag and the linker region between the tag and the protein. Such experiments resulted in a total of 21 fragment ions, ( $4 \mathrm{~b}$-ions and $17 \mathrm{y}$-ions), and 100\% sequence coverage. (Open square: $-\mathrm{NH}_{3}$; filled circle: $-\mathrm{H}_{2} \mathrm{O}$; asterisk: electronic noise).

this case a human His-tagged $\mathrm{UbCH} 10$ protein isolated from HeLa cells. One of the major problems encountered while working with proteins from intact cells is that the spectra are often complex, and there is a high probability that the peak of interest may lie close to an interfering peak. Having a resolving quadrupole capable of unit $\mathrm{m} / \mathrm{z}$ resolution can be useful for the "gasphase" purification of an ion of interest from a complex mixture of ions. Even more importantly, Q1 can be used to isolate a particular ion from a complex mixture and accumulate only that ion in the ICR cell so that space charge from other ions does not affect the accuracy of the mass measurement. This ability to select an isotopic cluster (from a highly charged protein ion distribution) in the ICR cell can be an important advantage where accurate measurement of a large protein ion is required. A human UbCH10 protein (MW 19639) was analyzed by top-down methods using this instrument. The recombinant protein, UbCH10 (MW 20591), had ambiguous $\mathrm{N}$ - and C-termini as the DNA sequence information obtained for this clone was not of good quality; thus, the goal was to verify the cloning site and the nature of the tag for this protein using top-down methods. Recombinant human His-tagged UbCH10 was "crudely" purified (see Experimental section) and the resulting mixture ${ }^{\circ}$ was $^{\circ}$ analyzed ${ }^{\circ}$ using $^{\circ}$ the ${ }^{\circ}$ hybrid ${ }^{\circ}$ instrument ${ }^{\circ}$ (Figure 9). ${ }^{\circ}$ Apart ${ }^{\circ}$ from ${ }^{\circ}$ the ${ }^{\circ}$ different $^{\circ}$ charge $^{\circ}$ states $^{\circ}$ of $f^{\circ}$ the ${ }^{\circ}$ main component, $\mathrm{UbCH} 10$, several other species, some with similar masses, are apparent in the FTMS spectrum (a portion ${ }^{\circ}$ of $^{\circ}$ the ${ }^{\circ}$ spectrum ${ }^{\circ} s^{\circ}$ shown $^{\circ}$ in $^{\circ}$ the ${ }^{\circ}$ inset ${ }^{\circ}$ of ${ }^{\circ}$ Figure 10). ${ }^{\circ} \mathrm{Q} 1^{\circ}$ was $^{\circ}$ used $^{\circ}$ at $^{\circ}$ unit $^{\circ}{ }^{\circ}$ resolution ${ }^{\circ}$ to $^{\circ}$ isolate ${ }^{\circ}$ the ${ }^{\circ}\left[\mathrm{M}^{\circ}+\right.$
$24 \mathrm{H}]^{24+}$ ion from the adjacent peak $\sim 1 \mathrm{~m} / \mathrm{z}$ higher, allowing a relatively clean CAD spectrum of the protonated ions to be obtained without interference from the sodiated species. The mass of the intact protein was determined from the measured $\mathrm{m} / \mathrm{z}$ of the isotopic cluster ions. The measured value of the protein was 20593.29 Da. Since the theoretical value of the protein is 20591.32 Da, this result indicated that the predicted disulfide bond between the Cys102 and Cys114 was reduced. Fragment ions of the parent ion at $\mathrm{m} / \mathrm{z} 858.9$ were accumulated for $1.5 \mathrm{~s}$ (it was observed that if accumulation times longer than $1 \mathrm{~s}$ were used, charge stripping and fragmentation of the initially trapped ions resulted). A total pulse sequence of $5 \mathrm{~s}$ averaged for 5 scans was used to obtain the Q2 CAD spectrum shown in ${ }^{\circ}$ Figure ${ }^{\circ} 9$.

The spectra were analyzed by an in-house program called $^{\circ}$ MasSpike $^{\circ}[62]{ }^{\circ}$ similar $^{\circ}$ to $^{\circ}$ Thrash $^{\circ}[63],{ }^{\circ}$ which reduces each spectrum into the monoisotopic peak list of the fragment ions. This program operates by identifying isotopic clusters based on $\mathrm{S} / \mathrm{N}$ ratio. A matched filter approach was then employed to determine the charge state of the individual isotopic clusters. The resulting charge state information allows the generation

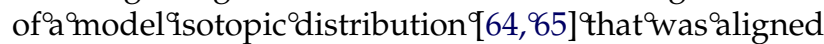
with the observed isotopic distribution. This alignment was achieved using a maximum likelihood comparison between the observed isotopic distribution and its theoretical counterpart. The output peak list was then compared with MS fragmentation output of the molecule from GPMAW 6.0 (Lighthouse Software, Odense, 
Denmark) to reveal the identity of the ions. A total of 40 fragment ions were identified from the spectrum and covered the complete sequence of the protein. Twentyone unique ions (17 $\mathrm{y}$-ions and $4 \mathrm{~b}$-ions) were identified using the most abundant fragment ions after taking into account the multiple charge states for the same fragment ion. Unfortunately, a number of ions could not be identified in this spectrum. Some of these ions could be a result of incomplete desolvation in the source or secondary fragmentation in Q2.

Sometimes, a cloning site can shift the open reading frame (ORF), resulting in changes in protein size/ sequence. In this case the $5^{\prime}$ cloning site was not well characterized by nucleotide sequencing methods and restriction enzyme mapping. However, since the translation product (the protein) was available, it proved possible to obtain information about the $5^{\prime}$ cloning site. The MS and $\mathrm{MS}^{2}$ spectra verified the sites used for the cloning and identified the $5^{\prime}$ linker region $\mathrm{N}$-terminal to the C-terminal His-tag that had been introduced to facilitate purification. Previous attempts to characterize this region by bottom-up approaches had failed because the peptide containing this sequence stretch was not observed. Using the $\mathrm{MS}^{\mathrm{n}}$ capability of the qQq-FTMS system, obtaining fragment ions for all possible cleavages was found to be possible and, thus, the hybrid instrument was shown to be useful for the detailed characterization and de novo sequencing of proteins. The mass spectra of proteins from biological sources, both recombinant and otherwise, often exhibit unusual mass shifts due to sequence variation and or posttranslational ${ }^{\circ}$ modifications ${ }^{\circ}$ of ${ }^{\circ}$ the ${ }^{\circ}$ proteins ${ }^{\circ}\left[66,{ }^{\circ} 67\right] .^{\circ}$ The mass spectrum of $\mathrm{UbCH} 10$ also included some signals having mass shifts that provide evidence of post-translational modifications which will be discussed elsewhere, in more detail.

\section{Conclusions}

The advantages of this new hybrid instrument for biological applications were highlighted in this study. Although a special emphasis was placed on the analysis of phosphopeptides, other modifications have been investigated and will be described in subsequent publications. This instrument appeared to be particularly useful for the analysis of labile modifications, primarily because of the ability to selectively accumulate specific low abundance species and apply different fragmentation methods. This gives one the choice of fragmentation methods when dealing with a diversity of biological samples that behave very differently. For example, Q2 CAD was very useful for the fragmentation and localization of phosphorylation sites on serine and threonine phosphopeptides because of the "signature" dehydroalanine and dehydroaminobutyric acid ions formed upon loss of the phosphate moiety, $\mathrm{H}_{3} \mathrm{PO}_{4}$. However, this method cannot be used for O-glycosylated peptides because the loss of the sugar moiety upon fragmentation usually does not leave a "signa- ture", with the result that the original position of the glycan moiety cannot be determined. Thus, to localize the site of glycosylation, backbone directed fragmenta-

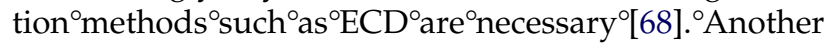
important consideration when analyzing biological samples is ${ }^{\circ}$ that ${ }^{\circ}$ ion ${ }^{\circ}$ optics ${ }^{\circ}$ must ${ }^{\text {be }}$ tuned ${ }^{\circ}$ for ${ }^{\circ}$ the ${ }^{\circ}$ sample, particularly when analyzing peptides with labile substituents. Thus, it is important that the control parameters of the ion optics are available to the instrument user. For example, if one wished to perform LC/MS analysis of a sample containing phosphopeptides, the instrument could be optimized and tuned to avoid loss of the phosphate moiety before fragmentation and the appropriate fragmentation method could be selected. Furthermore, the trapping/accumulation time can differ from one mass range to another and should be tuned accordingly. Because of the time-of-flight effect inherent in any external ion source FTMS, it is critical to be able to adjust the ICR gated trapping parameters to maximize $^{\circ}$ signal $^{\circ}[69] .{ }^{\circ}$ Another ${ }^{\circ}$ parameter $^{\circ}$ that $^{\circ}$ could $^{\circ}$ be optimized on the instrument is the frequency and amplitude of the rf applied to the hexapoles to transfer ions from Q2 to the ICR cell. Whereas these parameters are not so sharply defined in the useable range, over large $m / z$ ranges it is important to optimize these values, as they vary depending on the mass of the analyte.

The detection limits of the instrument were demonstrated here to be in the low $\mathrm{fmol} / \mu \mathrm{L}$ (nanomolar range) for biological samples and $10 \mathrm{amol} / \mu \mathrm{L}$ for synthetic samples, as a result of the ion transmission efficiency of the instrument. Another feature was the option to employ the Q2 LINAC collision cell, which improved the extraction efficiency of ions in the collision cell by the application of a small axial electric field in the quadrupole without placing severe limits on the ion transmission $^{\circ}$ window ${ }^{\circ}[28,29]$. The use $^{\circ}$ of ${ }^{\circ}{ }^{\circ}$ quadru- $^{\circ}$ pole collision cell provided the important ability to detect a wide range of fragment ions during $\mathrm{MS}^{2}$ experiments, in contrast to the more limited range available in an ion trap. In an ion trap, where radial excitation is used to fragment the precursors, fragment ions below $1 / 3$ of the precursor mass cannot be observed because of the need to employ a moderately large q-value to confine and fragment the precursor ion. Thus, employing the $\mathrm{qQq}$ configuration as the first stage of this instrument provides a significant advantage in accessible fragment ion mass range, in comparison to an ion trap. The importance of high mass accuracy and high resolving power for identifying peptides ${ }^{\circ}[70]^{\circ}$ and $^{\circ}$ modifications $^{\circ}$ on $^{\circ}$ peptides $^{\circ}[71,072]$ has been illustrated in several studies. The first of these studies used characteristic ions in the low mass region ( $\mathrm{y}_{1}, \mathrm{y}_{2}, \mathrm{a}_{2}, \mathrm{~b}_{2}$, and $\mathrm{b}_{3}$ ions) with mass accuracy data ${ }^{\circ}{ }^{\circ}$ the ${ }^{\circ}$ low $^{\circ}$ ppm $^{\circ}$ range, ${ }^{\circ}$ to $^{\circ}$ identify ${ }^{\circ}$ proteins ${ }^{\circ}[70]$. The latter two studies showed that high resolution, high accuracy data in low mass regions enabled the detection of modified peptides based on characteristic modifications to specific ions. These could be clearly resolved from other interfering fragment ions 
and, thus, differentiated the modified peptides from unmodified peptides that produce fragments of the same $^{\circ}$ nominal ${ }^{\circ} \operatorname{mass}^{\circ}\left[71,{ }^{\circ} 72\right]$.

Other advantages of this collision cell, in comparison to a normal multipole, include limiting reactions between buffer gas molecules and ions, having the option to operate the cell at the same pressure in MS and CAD modes, and limiting the cross-talk between consecutive experiments. The operating speed of this instrument for both $\mathrm{MS}^{1}$ and $\mathrm{MS}^{2}$ modes results from its ability to rapidly select precursor ions with Q1 without the need to trap and eject other ions, as in an ion trap, and to fragment and cool ions in Q2 before transfer of the ions into the ICR cell, thus eliminating the need for collision gas in the ICR cell and the time associated with pumping it out before ion detection.

The most significant aspect of this instrument was its versatility for addressing a number of different biological problems. Combining the qQq commercial front end with an ICR mass analyzer has resulted in a number of improvements: increased selectivity of precursor ion species, increased sensitivity, increased experimental speed, and the availability of different fragmentation methods. All these factors made this instrument particularly useful for the biological applications described here.

\section{Acknowledgments}

The authors acknowledge Hanno Steen for reading the manuscript critically and Jason J. Cournoyer and Vera Ivleva for their technical support. This research was supported by NSERC of Canada (JAJ), MDS SCIEX (PBO, BAT), NIH/NCRR P41 RR10888 (CEC), NIH/NHLBI N01 HV28178 (CEC), and the ACS Petroleum Research Fund (PBO).

\section{References}

1. Costello, C. E. Time, life... and mass spectrometry. New techniques to address biological questions. Biophys. Chem. 1997, 68, 173-188.

2. Karas, M.; Hillenkamp, F. Laser desorption ionization of proteins with molecular masses exceeding 10,000 Daltons. Anal. Chem. 1988, 60, 2299-2301.

3. Zubarev, R. A.; Kelleher, N. L.; McLafferty, F. W. Electron capture dissociation of multiply charged protein cations-a nonergodic process. J. Am. Chem. Soc. 1998, 120, 3265-3266.

4. Zubarev, R. A.; Kruger, N. A.; Fridriksson, E. K.; Lewis, M. A.; Horn, D. M.; Carpenter, B. K.; McLafferty, F. W. Electron capture dissociation of gaseous multiply-charged proteins is favored at disulfide bonds and other sites of high hydrogen atom affinity. J. Am. Chem. Soc. 1999, 121, 2857-2862.

5. Leymarie, N.; Costello, C. E.; O'Connor, P. B. Electron capture dissociation initiates a free radical reaction cascade. J. Am. Chem. Soc. 2003, 125, 8949-8958.

6. Syka, J. E.; Coon, J. J.; Schroeder, M. J.; Shabanowitz, J.; Hunt, D. F. Peptide and protein sequence analysis by electron transfer dissociation mass spectrometry. Proc. Natl. Acad. Sci. U.S.A. 2004, 101, 9528-9533.

7. Kelleher, R. L.; Zubarev, R. A.; Bush, K.; Furie, B.; Furie, B. C.; McLafferty, F. W.; Walsh, C. T. Localization of labile posttranslational modifications by electron capture dissociation: The case of $\gamma$-carboxyglutamic acid. Anal. Chem. 1999, 71, 42504253.

8. Stensballe, A.; Jensen, O. N.; Olsen, J. V.; Haselmann, K. F.; Zubarev, R. A. Electron capture dissociation of singly and multiply phosphorylated peptides. Rapid Commun. Mass Spectrom. 2000, 14, 1793-1800.

9. Shi, S. D. H.; Hemling, M. E.; Carr, S. A.; Horn, D. M.; Lindh, I.; McLafferty, F. W. Phosphopeptide/phosphoprotein mapping by electron capture dissociation mass spectrometry. Anal. Chem. 2001, 73, 19-22.

10. Mirgorodskaya, E.; Roepstorff, P.; Zubarev, R. A. Localization of O-glycosylation sites in peptides by electron capture dissociation in a Fourier transform mass spectrometer. Anal. Chem. 1999, 71, 4431-4436.

11. Silivra, O. A.; Kjeldsen, F.; Ivonin, I. A.; Zubarev, R. A. Electron capture dissociation of polypeptides in a threedimensional quadrupole ion trap: Implementation and first results. J. Am. Soc. Mass Spectrom. 2005, 16, 22-27.

12. Baba, T.; Hashimoto, Y.; Hasegawa, H.; Hirabayashi, A.; Waki, I. Electron capture dissociation in a radio frequency ion trap. Anal. Chem. 2004, 76, 4263-4266.

13. Palmblad, M.; Wetterhall, M.; Markides, K.; Hakansson, P.; Bergquist, J. Analysis of enzymatically digested proteins and protein mixtures using a 9.4 tesla Fourier transform ion cyclotron mass spectrometer. Rapid Commun. Mass Spectrom. 2000, 14, 1029-1034.

14. Green, M. K.; Johnston, M. V.; Larsen, B. S. Mass accuracy and sequence requirements for protein database searching. Anal. Biochem. 1999, 275, 39-46.

15. Conrads, T. P.; Anderson, G. A.; Veenstra, T. D.; Pasa-Tolic, L.; Smith, R. D. Utility of accurate mass tags for proteome-wide protein identification. Anal. Chem. 2000, 72, 3349-3354.

16. Zubarev, R. A.; Hakansson, P.; Sundqvist, B. Accuracy requirements for peptide characterization by monoisotopic molecular mass measurements. Anal. Chem. 1996, 68, 4060-4063.

17. Strittmatter, E. F.; Ferguson, P. L.; Tang, K.; Smith, R. D. Proteome analyses using accurate mass and elution time peptide tags with capillary LC time-of-flight mass spectrometry. J. Am. Soc. Mass Spectrom. 2003, 14, 980-991.

18. Olsen, J. V.; Ong, S. E.; Mann, M. Trypsin cleaves exclusively C-terminal to arginine and lysine residues. Mol. Cell. Proteom. 2004, 3, 608-614.

19. Hughey, C. A.; Rodgers, R. P.; Marshall, A. G. Resolution of 11,000 compositionally distinct components in a single electrospray ionization Fourier transform ion cyclotron resonance mass spectrum of crude oil. Anal. Chem. 2002, 74, 4145-4149.

20. Spengler, B. De novo sequencing, peptide composition analysis, and composition-based sequencing: A new strategy employing accurate mass determination by Fourier transform ion cyclotron resonance mass spectrometry. J. Am. Soc. Mass Spectrom. 2004, 15, 703-714.

21. Kelleher, N. L.; Taylor, S. V.; Grannis, D.; Kinsland, C.; Chiu, H. J.; Begley, T. P.; McLafferty, F. W. Efficient sequence analysis of the six gene products $(7-74 \mathrm{kDa})$ from the Escherichia coli thiamin biosynthetic operon by tandem high-resolution mass spectrometry. Protein Sci. 1998, 7, 1796-1801.

22. Mann, M.; Wilm, M. Error-tolerant identification of peptides in sequence databases by peptide sequence tags. Anal. Chem. 1994, 66, 4390-4399.

23. Eng, J. K.; McCormack, A. L.; Yates, J. R. I. An approach to correlate tandem mass spectral data of peptides with amino acid sequences in a protein database. J. Am. Soc. Mass Spectrom. 1994, 5, 976-989.

24. McLafferty, F. W. High-resolution tandem FT mass spectrometry above $10 \mathrm{kDa}$. Acc. Chem. Res. 1994, 27, 379-386.

25. Kelleher, N. L.; Costello, C. A.; Begley, T. P.; McLafferty, F. W. Thiaminase I (42 kDa) heterogeneity, sequence refinement, 
and active site location from high-resolution tandem mass spectrometry. J. Am. Soc. Mass Spectrom. 1995, 6, 981-984.

26. Mortz, E.; Oconnor, P. B.; Roepstorff, P.; Kelleher, N. L.; Wood, T. D.; McLafferty, F. W.; Mann, M. Sequence tag identification of intact proteins by matching tandem mass spectral data against sequence data bases. Proc. Natl. Acad. Sci. U.S.A. 1996, 93, 8264-8267.

27. Pittman, J. L.; Thomson, B. A.; Budnik, B. A.; Cournoyer, J. J.; Fallows, E.; Jebanathirajah, J. A.; Moyer, S. C.; Costello, C. E.; O'Connor, P. B. A novel hybrid instrument using a commercial electrospray ionization source with a high-performance FTMS for proteomics applications. Proceedings of the 52nd Conference of the American Society of Mass Spectrometry; Memphis, TN, May 2004.

28. Loboda, A.; Krutchinsky, A.; Loboda, O.; McNabb, J.; Spicer, V.; Ens, W.; Standing, K. G. Novel linac II electrode geometry for creating an axial field in a multipole ion guide. Eur. J. Mass Spectrom. 2000, 6, 531-536.

29. Wilcox, B. E.; Hendrickson, C. L.; Marshall, A. G. Improved ion extraction from a linear octopole ion trap: SIMION analysis and experimental demonstration. J. Am. Soc. Mass Spectrom. 2002, 13, 1304-1312.

30. McFarland, M. A.; Hendrickson, C. L.; Marshall, A. G. Ion "threshing": Collisionally activated dissociation in an external octopole ion trap by oscillation of an axial electric potential gradient. Anal. Chem. 2004, 76, 1545-1549.

31. Pittman, J. L.; O'Connor, P. B. A minimum thickness gate valve with integrated ion optics for mass spectrometry. J. Am. Soc. Mass Spectrom. 2005, 16, 441-445.

32. Beu, S. C.; Laude, D. A., Jr. Open trapped ion cell geometries for FT/ICR/MS. Int. J. Mass Spectrom. Ion Processes 1992, 112, 215-230.

33. Marshall, A. G.; Wang, T.-C. L.; Ricca, T. L. Tailored excitation for Fourier transform ion cyclotron resonance mass spectrometry. J. Am. Chem. Soc. 1985, 107, 7893-7897.

34. Gauthier, J. W.; Trautman, T. R.; Jacobson, D. B. Sustained off-resonance irradiation for collision-activated dissociation involving Fourier-transform mass spectrometry collision-activated dissociation technique that emulates infrared multiphoton dissociation. Anal. Chim. Acta 1991, 1, 211-225.

35. Little, D. P.; Speir, J. P.; Senko, M. W.; O'Connor, P. B.; McLafferty, F. W. Infrared multiphoton dissociation of large multiply-charged ions for biomolecule sequencing. Anal. Chem. 1994, 66, 2809-2815.

36. Mirgorodskaya, E.; O'Connor, P. B.; Costello, C. E. A general method for precalculation of parameters for sustained off resonance irradiation/collision-induced dissociation. J. Am. Soc. Mass Spectrom. 2002, 13, 318-324.

37. Belov, M. E.; Anderson, G. A.; Angell, N. H.; Shen, Y. F.; Tolic, N.; Udseth, H. R.; Smith, R. D. Dynamic range expansion applied to mass spectrometry based on data-dependent selective ion ejection in capillary liquid chromatography Fourier transform ion cyclotron resonance for enhanced proteome characterization. Anal. Chem. 2001, 73, 5052-5060.

38. Senko, M. W.; Hendrickson, C. L.; Pasatolic, L.; Marto, J. A.; White, F. M.; Guan, S. H.; Marshall, A. G. Electrospray ionization Fourier transform ion cyclotron resonance at 9.4 T. Rapid Commun. Mass Spectrom. 1996, 10, 1824-1828.

39. Senko, M. W.; Hendrickson, C. L.; Emmett, M. R.; Shi, S. D. H.; Marshall, A. G. External accumulation of ions for enhanced electrospray ionization Fourier transform ion cyclotron resonance mass spectrometry. J. Am. Soc. Mass Spectrom. 1997, 8, 970-976.

40. Patrie, S. M.; Charlebois, J. P.; Whipple, D.; Kelleher, N. L.; Hendrickson, C. L.; Quinn, J. P.; Marshall, A. G.; Mukhopadhyay, B. Construction of a hybrid quadrupole/Fourier transform ion cyclotron resonance mass spectrometer for versatile MS/MS above $10 \mathrm{kDa}$. J. Am. Soc. Mass Spectrom. 2004, 15, 1099-1108.

41. Shevchenko, A.; Wilm, M.; Vorm, O.; Mann, M. Mass spectrometric sequencing of proteins silver-stained polyacrylamide gels. Anal. Chem. 1996, 68, 850-858.

42. Rappsilber, J.; Ishihama, Y.; Mann, M. Stop and go extraction tips for matrix-assisted laser desorption/ionization, nanoelectrospray, and LC/MS sample pretreatment in proteomics. Anal. Chem. 2003, 75, 663-670.

43. Gobom, J.; Nordhoff, E.; Mirgorodskaya, E.; Ekman, R.; Roepstorff, P. Sample purification and preparation technique based on nano-scale reversed-phase columns for the sensitive analysis of complex peptide mixtures by matrix-assisted laser desorption/ionization mass spectrometry. J. Mass Spectrom. 1999, 34, 105-116.

44. Marshall, A. G.; Hendrickson, C. L.; Shi, S. D. Scaling MS plateaus with high-resolution FT-ICRMS. Anal. Chem. 2002, 74, 252A-259A.

45. Cournoyer, J. J.; Pittman, J. L.; Ivleva, V. B.; Fallows, E.; Waskell, L.; Costello, C. E.; O'Connor, P. B. Deamidation: Differentiation of aspartyl from isoaspartyl products in peptides by electron capture dissociation. Protein Sci. 2005, 14, 452-463.

46. Wilm, M.; Mann, M. Analytical properties of the nanoelectrospray ion source. Anal. Chem. 1996, 68, 1-8.

47. Valaskovic, G. A.; Kelleher, N. L.; Little, D. P.; Aaserud, D. J.; McLafferty, F. W. Attomole-sensitivity electrospray source for large-molecule mass spectrometry, Anal. Chem. 1995, 67, 38023805.

48. Stemmann, O.; Zou, H.; Gerber, S. A.; Gygi, S. P.; Kirschner, M. W. Dual inhibition of sister chromatid separation at metaphase. Cell 2001, 107, 715-726.

49. Tsybin, Y. O.; Hakansson, P.; Budnik, B. A.; Haselmann, K. F.; Kjeldsen, F.; Gorshkov, M.; Zubarev, R. A. Improved lowenergy electron injection systems for high rate electron capture dissociation in Fourier transform ion cyclotron resonance mass spectrometry. Rapid Commun. Mass Spectrom. 2001, 15, 1849-1854.

50. Budnik, B. A.; Haselmann, K. F.; Zubarev, R. A. Electron detachment dissociation of peptide di-anions: An electronhole recombination phenomenon. Chem. Phys. Lett. 2001, 342, 299-302.

51. Kelleher, N. L.; Lin, H. Y.; Valaskovic, G. A.; Aaserud, D. J.; Fridriksson, E. K.; McLafferty, F. W. Top-down versus bottom-up protein characterization by tandem high-resolution mass spectrometry. J. Am. Chem. Soc. 1999, 121, 806-812.

52. Hopkins, C. E.; O'Connor, P. B.; Allen, K. N.; Costello, C. E.; Tolan, D. R. Chemical-modification rescue assessed by mass spectrometry demonstrates that gamma-thia-lysine yields the same activity as lysine in aldolase. Protein Sci. 2002, 11, 1591-1599.

53. Nemeth-Crawley, J.; Rouse, J. Identification and sequencing analysis of intact proteins via collision-induced dissociation and quadrupole time-of-flight mass spectrometry. J. Mass Spectrom. 2002, 37, 270-282.

54. Thevis, M.; Loo, R. R. O.; Loo, J. A. Mass spectrometric characterization of transferrins and their fragments derived by reduction of disulfide bonds. J. Am. Soc. Mass Spectrom. 2003, 14, 635-647.

55. Ginter, J. M.; Zhou, F.; Johnston, M. V. Generating protein sequence tags by combining cone and conventional collision induced dissociation in a quadrupole time-of-flight mass spectrometer. J. Am. Soc. Mass Spectrom. 2004, 15, 1478-1486.

56. Meng, F.; Du, Y.; Miller, L. M.; Patrie, S. M.; Robinson, D. E.; Kelleher, N. L. Molecular-level description of proteins from Saccharomyces cerevisiae using quadrupole FT hybrid mass 
spectrometry for top-down proteomics. Anal. Chem. 2004, 76, 2852-2858.

57. Du, Y.; Meng, F. Y.; Patrie, S. M.; Miller, L. M.; Kelleher, N. L. Improved molecular weight-based processing of intact proteins for interrogation by quadrupole-enhanced FT MS/MS. J. Proteome Res. 2004, 3, 801-806.

58. Horn, D. M.; Zubarev, R. A.; McLafferty, F. W. Automated reduction and interpretation of high resolution electrospray mass spectra of large molecules. J. Am. Soc. Mass Spectrom. 2000, 11, 320-332.

59. Taylor, G. K.; Kim, Y. B.; Forbes, A. J.; Meng, F.; McCarthy, R.; Kelleher, N. L. Web and database software for identification of intact proteins using top-down mass spectrometry. Anal. Chem. 2003, 75, 4081-4086.

60. LeDuc, R. D.; Taylor, G. K.; Kim, Y. B.; Januszyk, T. E.; Bynum, L. H.; Sola, J. V.; Garavelli, J. S.; Kelleher, N. L. ProSight PTM: An integrated environment for protein identification and characterization by top-down mass spectrometry. Nucleic Acids Res. 2004, 32, W340-345.

61. Forbes, A. J.; Patrie, S. M.; Taylor, G. K.; Kim, Y. B.; Jiang, L.; Kelleher, N. L. Targeted analysis and discovery of posttranslational modifications in proteins from Methanogenic archaea by top-down MS. Proc. Natl. Acad. Sci. U.S.A. 2004, 101, 26782683.

62. Kaur, P.; Aizikov, K.; O'Connor, P. B. Improved algorithms for interpretation of high resolution mass spectra. Proceedings of the 52nd Conference of the American Society of Mass Spectrometry; Memphis, TN, May 2004.

63. Horn, D. M.; Zubarev, R. A.; McLafferty, F. W. Automated de novo sequencing of proteins by tandem high-resolution mass spectrometry. Proc. Natl. Acad. Sci. U.S.A. 2000, 97, 10313-10317.

64. Senko, M. W.; Beu, S. C.; McLafferty, F. W. Determination of monoisotopic masses and ion populations for large biomol- ecules from resolved isotopic distributions. J. Am. Soc. Mass Spectrom. 1995, 6, 229-233.

65. Rockwood, A. L.; Vanorden, S. L. Ultrahigh-speed calculation of isotope distributions. Anal. Chem. 1996, 68, 2027-2030.

66. Geoghegan, K. F.; Dixon, H. B. F.; Rosner, P. J.; Hoth, L. R.; Lanzetti, A. J.; Borzilleri, K. A.; Marr, E. S.; Pezzullo, L. H.; Martin, L. B.; LeMotte, P. K.; McColl, A. S.; Kamath, A. V.; Stroh, J. G. Spontaneous $\alpha$-N-6-phosphogluconoylation of a "His tag" in Escherichia coli: The cause of extra mass of 258 or $178 \mathrm{Da}$ in fusion proteins Anal. Biochem. 1999, 267, 169-184.

67. Seo, J.; Lee, K. J. Post-translational modifications and their biological functions: Proteomics analysis and systematic approaches. J. Biochem. Mol. Biol.. 2004, 37, 35-44.

68. Mirgorodskaya, E.; Hassan, H.; Clausen, H.; Roepstorff, P. Mass spectrometric determination of O-glycosylation sites using $\beta$-elimination and partial acid hydrolysis. Anal. Chem. 2001, 73, 1263-1269.

69. O'Connor, P. B.; Duursma, M. C.; van Rooij, G. J.; Heeren, R. M. A.; Boon, J. J. Correction of time of flight shifted polymeric molecular weight distributions in MALDI-FTMS. Anal. Chem. 1997, 69, 2751-2755.

70. Nielsen, M. L.; Bennett, K. L.; Larsen, B.; Moniatte, M.; Mann, M. Peptide end sequencing by orthogonal MALDI tandem mass spectrometry. J. Proteome Res. 2002, 1, 63-71.

71. Jebanathirajah, J.; Steen, H.; Roepstorff, P. Using optimized collision energies and high resolution, high accuracy fragment ion selection to improve glycopeptide detection by precursor ion scanning. J. Am. Soc. Mass Spectrom. 2003, 14, 777-784.

72. Steen, H.; Kuster, B.; Fernandez, M.; Pandey, A.; Mann, M. Detection of tyrosine phosphorylated peptides by precursor ion scanning quadrupole TOF mass spectrometry in positive ion mode. Anal. Chem. 2001, 73, 1440-1448. 